Bull. Mater. Sci., Vol. 2, Number 1, January 1980, pp. 31-33. (C) Printed in India.

\title{
Nucleation and growth of potassium dihydrogen phosphate crystals in silica gels
}

\author{
M S JOSHI and A V ANTONY \\ Department of Physics, Sardar Patel University, Vallabh Vidyanagar 388120
}

MS received 24 September 1979; revised 19 November 1979

\begin{abstract}
Kinetic studies on nucleation and growth of potassium dihydrogen phosphate crystals in silica gels show that the rate-determining process for the growth of these crystals in silica gels is diffusion. Morphology, microhardness and perfection of gel grown crystals are also reported.
\end{abstract}

Keywords. Kinetic studies ; nucleation ; potassium dihydrogen phosphate crystals ; silica gel.

Potassium dihydrogen phosphate (KDP) belongs to the scalenohedral class of tetragonal crystal system and crystallises from aqueous solutions in anhydrous form. Henisch et al (1965), Banks et al (1973) and Cho et al (1977) have used gel techniques for the growth of transparent single crystals. Recently (Brezina and Havrankova (1971) and Joshi and Antony $(1978,1979)$ have reported the growth of KDP crystals in gels. Kinetic studies on nucleation and growth of KDP crystals in silica gels are reported in this paper. The morphology, microhardness and perfection of gel-grown crystals are also reported.

The apparatus, materials used and experimental procedure are reported in Joshj and Antony (1978). Alcohol was used to crystallise KDP incorporated in gel by reducing its solubility. Variation in solubility of KDP with concentration of alcohol is illustrated in figure 1, Nucleation and growth characteristics were studied with a travelling microscope.

Figure 2 is a photograph of crystals grown in silica gels by the above method. Nucleation of KDP crystals varied with $\mathrm{pH}$ and gel ageing. The effect of $\mathrm{pH}$ of the gel on the growth of KDP crystals was studied with gels of different $\mathrm{pH}$ values (ranging from $5 \cdot 1$ to $6 \cdot 2$ ) and gel ageing. Figure $3(\mathrm{a})$ is a plot of distance of precipitation front (which is a function of rate of diffusion of alcohol into the gel) against time, whereas figure 3 (b) is a plot of the number of nuclei against time. It is observed that with increase in $\mathrm{pH}$, diffusion rate and the number of nuclej decrease thus indicating that the nuclej formed earlier grow bigger in size and fresh nucleation is reduced.

Growth characteristics of KDP crystals were studied using gels of same pH and gel ageing. Length of an isolated crystal was measured at fixed intervals of time. 


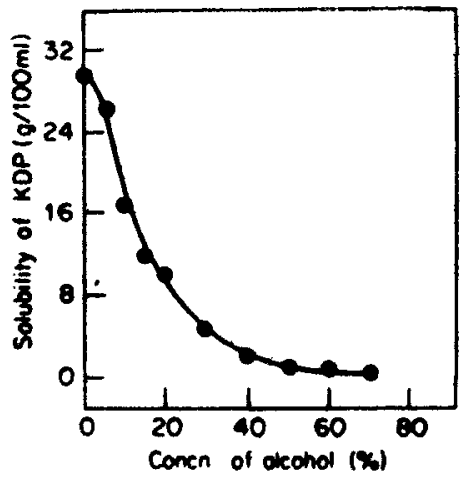

Figure 1. Solubility of KDP in water containing different amount of alcohol.

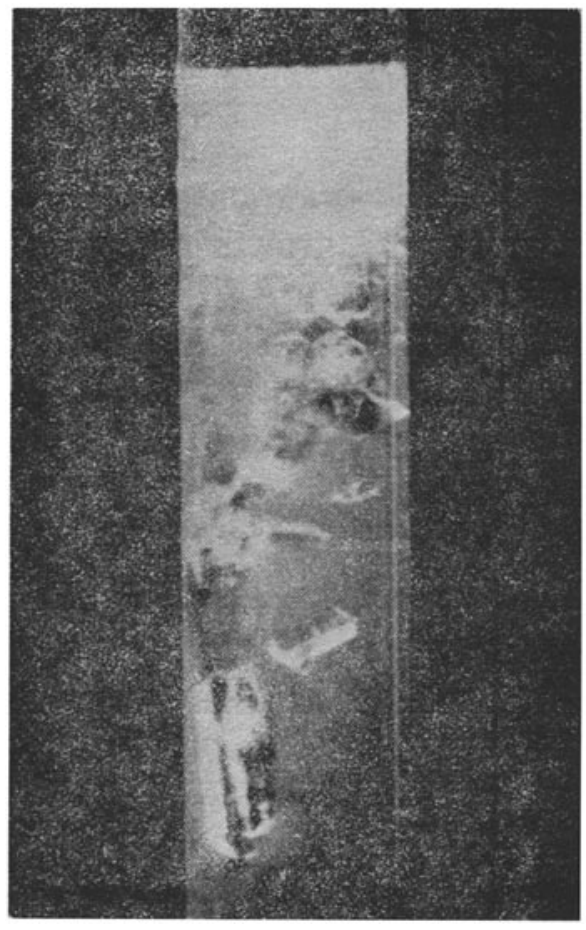

Figure 2. KDP crystals grown in silica gels at room temperature.
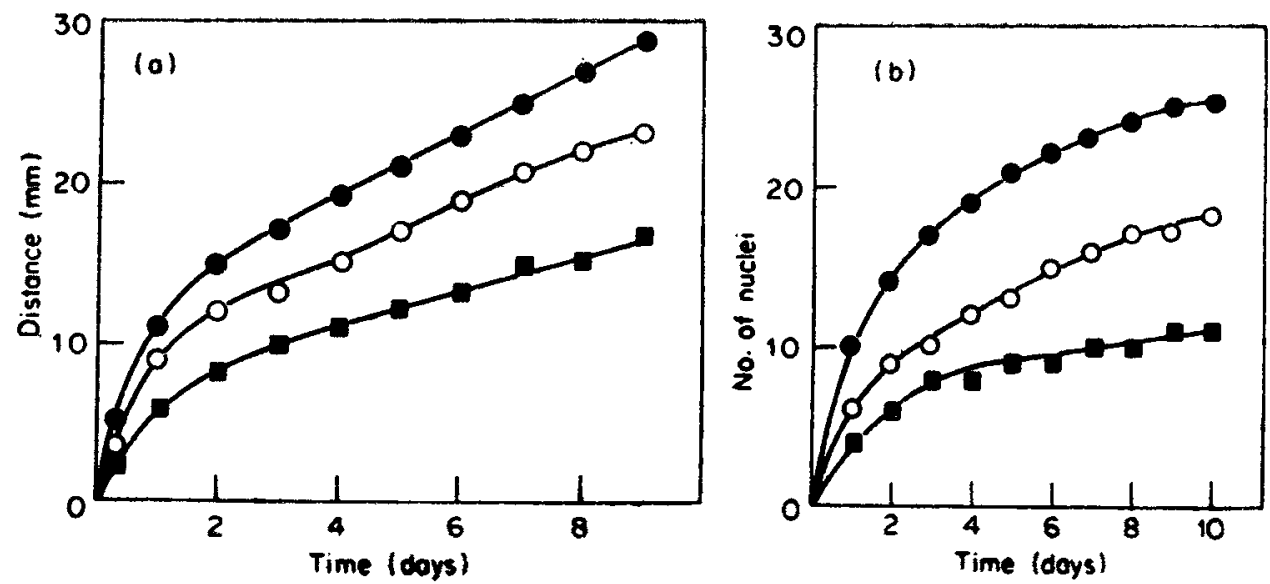

Ftgure 3. (a) A plot of distance of precipitation front with time. (b) A plot of number of nuclei produced versus time.

A linear relationship between (length) ${ }^{2}$ and time is observed which suggests that the rate-determining process (Frank 1950) is diffusion. However, the slopes of the curves vary with gel ageing, $\mathrm{pH}$ and the distance of crystals from the interface. 
Some KDP crystals grown near the interface in gels of $\mathrm{pH}$ value up to about $\mathbf{5 \cdot 2}$ were tapered due to low $\mathrm{pH}$ values of gel and the higher supersaturations at which crystals grow. The KDP crystals, when grown in gels of $\mathrm{pH}$ value 5.6 and concentration of KDP solution equal to $3 \mathrm{M}$, grow in the form of chain along $\langle 001\rangle$ and (011) direstions very near the interface. Transparency and size of crystallites composing a chain increase with distance from the interface.

Microhardness of gel-grown KDP crystals was measured with a Vickers diamond indentor and the average microhardness was about $138 \mathrm{VHN}$ for a load of $20 \mathrm{~g}$. The crystals were etched in an etchant prepared by mixing $100 \mathrm{cc}$ glacial acetic acid with $10 \mathrm{cc}$ of $1 \mathrm{~N}$ sulphuric acid and the dislocation density was of the order of $10^{3}$ to $10^{4}$ per $\mathrm{cm}^{2}$.

\section{Acknowledgement}

One of us (AVA) is thankful to the Council of Scientific and Industrial Research, New Delhi, for a research fellowship.

\section{References}

Banks E, Chianelli R and Pintchovsky F 1973 J. Cryst. Growth 18185

Brezina B and Havrankova M 1971 Mater. Res. Bull. 6537

Cho S A, Gomez J A, Camisotti R and Ohep J C 1977 J. Mater. Sci. 12816

Frank F C 1950 Proc. R. Soc. (London) A201 586

Henisch H K, Dennis J and Hanoka I J 1965 J. Phys. Chem. Solids 26493

Joshi M S and Antony A V 1978 J. Mater. Sci. 13939

Joshi M S and Antony A V 1979 Krist. Tech. 14923 